\title{
Alveolar dead space and capnographic variables before and after thrombolysis in patients with acute pulmonary embolism
}

\author{
Marcos Mello Moreira' \\ Renato G G Terzi' \\ Carlos Heitor $\mathrm{N}$ Carvalho ${ }^{2}$ \\ Antonio Francisco de \\ Oliveira $\mathrm{Neto}^{3}$ \\ Mônica Corso Pereira ${ }^{4}$ \\ IIma Aparecida Paschoal ${ }^{4}$ \\ 'Department of Surgery, State \\ University of Campinas, School \\ of Medical Sciences; ${ }^{2}$ Department \\ of Cardiology, State University of \\ Campinas, School of Medical Sciences; \\ ${ }^{3}$ Intensive Care Unit of the State \\ University of Campinas, School of \\ Medical Sciences; ${ }^{4}$ Department of \\ Pulmonology, State University of \\ Campinas, School of Medical Sciences, \\ Campinas, Brazil
}

\begin{abstract}
Pulmonary embolism (PE) is a common condition. The central aim of this study was to describe the use of volumetric capnography (VCap) before and after fibrinolytic treatment of major PE. Lung scintigraphy was used as a base of comparison for the results of this treatment. We describe the cases of two conscious and spontaneously breathing patients (20- and 24-year-old women) with major PE undergoing thrombolysis. Curves of $\mathrm{CO}_{2}$ were obtained by VCap and associated with arterial blood gas analysis and D-dimer. The pattern of VCap was compared with the VCap of health volunteers. Parameters also calculated were: $\mathrm{P}(\mathrm{a}-\mathrm{et}) \mathrm{CO}_{2}$ gradient, alveolar dead space fraction (AVDSf), late dead space fraction (fDlate), and slope phase III (Slp III). The VCap results before and after thrombolysis for patients 1 and 2 were, respectively, $\mathrm{P}\left(\mathrm{a}\right.$-et) $\mathrm{CO}_{2}: 12.6$ to 5.8 and 7.9 to 1.6 (mmHg); AVDSf: 0.46 to 0.18 and 0.25 to 0.05; fDlate: 0.46 to 0.21 and 0.24 to 0.04 ; Slp III: 1.75 to 5.10 and 1.21 to $5.61(\mathrm{mmHg} / \mathrm{L})$. Lung scintigraphy was used to compare VCap results from the two subjects with VCap results from healthy volunteers and pigs before and after treatment associated with arterial blood gas, D-dimer, and showed satisfactory agreement.
\end{abstract}

Keywords: pulmonary embolism, capnography, respiratory dead space, thrombolysis, fibrin fibrinogen degradation products/fibrin fragment D

\section{Introduction}

Massive pulmonary embolism (PE) is a condition that presents as arterial hypotension, cardiogenic shock, and affects the preload of the left ventricular. ${ }^{1} \mathrm{PE}$ is characterized by an increase in dead alveolar space because of the lung areas that are ventilated but not perfused. The mortality rate among individuals with PE ranges from $10 \%$ to $25 \%$. Thrombolytic treatment, aimed at rapid dissolution of emboli is recommended. ${ }^{2}$ An effective demonstration of the efficacy of thrombolytic treatment in these patients is not always possible because the method considered to be the gold standard (pulmonary arteriography) is expensive, not always available, and carries a certain risk to the patient.

Noninvasive bedside techniques that aid in the diagnosis and evaluation of PE are based on respiratory parameters derived from the alveolar dead space. Using volumetric capnography (VCap), Eriksson and colleagues ${ }^{3}$ described a graphic method of extrapolating the arterial to end-tidal $\mathrm{CO}_{2}$ gradient $\left[\mathrm{P}(\mathrm{a}-\mathrm{et}) \mathrm{CO}_{2}\right]$ to a prolonged expiration. The authors dubbed this variable the alveolar late dead space fraction (fDlate).

Recently, Kline and colleagues ${ }^{4}$ and Rodger and colleagues ${ }^{5}$ used VCap in combination with determination of D-dimer (DD) levels, and gained good results from noninvasive bedside diagnosis, and follow-up evaluation of patients with PE.

The aim of this study was to compare ventilation/perfusion lung scintigraphy with the VCap variables before and after thrombolysis. Two conscious patients with acute 
PE were evaluated, and submitted to thrombolysis. The same evaluation protocol, as described below, was used in both cases.

The protocol was initiated with the patient calm and seated in a chair. The capnography monitor used was a $\mathrm{CO}_{2} \mathrm{SMO}$ Plus 8100 (Dixtal Biomédica, Manaus, Brazil), the sensor of which was connected to a mouthpiece. Nasal occlusion was achieved with a nose clip. Initially, the patient was allowed to breathe freely for $60 \mathrm{~s}$ in order to adapt to the new situation, after which monitoring began and arterial blood gases were collected from room air. The variables were recorded for a period of $4 \mathrm{~min}$ and stored on a computer using Analysis Plus ${ }^{\circledR}$ software. An offline sequence of the last 4 min of study was selected for analysis, to consider a variation of $<15 \%$ in expiratory tidal volume and of $<5 \%$ in $\mathrm{PetCO}_{2}$ obtained through VCap. Neither patient had a history of lung disease.

The capnographic variables used were: fDlate; (end-tidal) alveolar dead end space fraction (AVDSf); $\mathrm{P}(\mathrm{a}-\mathrm{et}) \mathrm{CO}_{2}$; and the phase III slope of the expirogram (Slp III).

The fDlate was calculated after determining extrapolated $\mathrm{PetCO}_{2}$ at $15 \%$ of the predicted total pulmonary capacity ${ }^{6}$ according to Eriksson and colleagues. ${ }^{3}$ The AVDSf was calculated using the formula:

$$
\text { AVDSf }=\mathrm{PaCO}_{2}-\mathrm{PetCO}_{2} / \mathrm{PaCO}_{2}
$$

where $\mathrm{PaCO}_{2}$ is arterial $\mathrm{CO}_{2}$ tension. ${ }^{5}$ The gradient $\mathrm{P}$ (a-et) $\mathrm{CO}_{2}$ was obtained by subtracting $\mathrm{PetCO}_{2}$ from $\mathrm{PaCO}_{2}$. The Slp III value was given directly by the Analysis Plus ${ }^{\circledR}$ program.

The DD levels were determined using rapid enzyme-linked immunosorbent assay (VIDAS D-dimer; bioMérieux, Marcy l'Étoile, France); cutoff $<500 \mathrm{ng} / \mathrm{ml}$.

\section{Case reports}

\section{Case I}

A 20-year-old female patient, using oral contraceptives and with a body mass index of $49 \mathrm{~kg} / \mathrm{m}^{2}$, presented with a 5 -day history of edema, erythema, and pain in the left calf. The patient complained of sudden chest pain, accompanied by dyspnea and cyanosis, which prompted her to seek medical attention at a health care clinic. She was later referred to the emergency room of a reference hospital.

Her physical examination showed good general health, a respiratory rate of $32 \mathrm{bpm}$, cyanosis of the extremities, a heart rate of $90 \mathrm{bpm}$, blood pressure of 160/100 $\mathrm{mmHg}$, and edema of the left leg with painful palpation of the left calf. An electrocardiogram revealed the $\mathrm{S}_{1} \mathrm{Q}_{3} \mathrm{~T}_{3}$ pattern.

Pulmonary scintigraphy showed signs of bilateral acute PE, affecting the superior, lateral, medial, anterior, basal, basolateral, and posterior basal segments of the right lung, and the anterior basal, basolateral, posterior basal, and inferior lingular segments of the left lung. Doppler ultrasound study of the lower limbs revealed deep vein thrombosis (DVT) in the left lower leg.

When the diagnosis of extensive PE was established, thrombolytic treatment with streptokinase (central catheter) was initiated; no complications resulted from the treatment. A second (control) pulmonary/perfusion scintigraphy was performed $36 \mathrm{~h}$ later, which showed an improvement in the scintigraphic pattern, with reperfusion of some segments of both lungs, principally the left lung.

\section{Case 2}

A 24-year-old female patient was referred to the emergency room of a referral center. She complained of sudden thoracic pain and dyspnea for two days. The patient stated that she had used oral contraceptives for two years, had never smoked, and had no history of cough or other respiratory symptoms of lung disease.

A physical examination showed that she was in good general health. She was conscious, alert, and dyspneic with a respiratory rate of $22 \mathrm{bpm}$, with no cyanosis of the extremities, a heart rate of $110 \mathrm{bpm}$, blood pressure of $160 / 100 \mathrm{mmHg}$, and no edema or tightening of the lower limbs. The electrocardiogram revealed the $\mathrm{S}_{1} \mathrm{Q}_{3} \mathrm{~T}_{3}$ pattern.

The lung scintigraphy was interpreted as positive for acute and extensive PE, affecting the entire right lung and a number of segments of the left lung (Figure 1). The Doppler ultrasound study of the lower limbs revealed no DVT. When the diagnosis of PE had been made, treatment with streptokinase (central catheter) began; no complications resulted from the treatment.

Seven months after discharge, during a follow-up visit to the outpatient clinic, when rising from a chair in the waiting room of the medical office, the patient presented tachypnea (30 bpm) and tachycardia (130 bpm). A new embolic event was suspected although a new scintigraphy showed no evidence of acute PE; a change in lung perfusion was no longer detected (Figure 2).

The study was approved by the Ethics Committee of the School of Medical Sciences of the State University of Campinas. The patients involved gave written informed consent to participate in this study. 


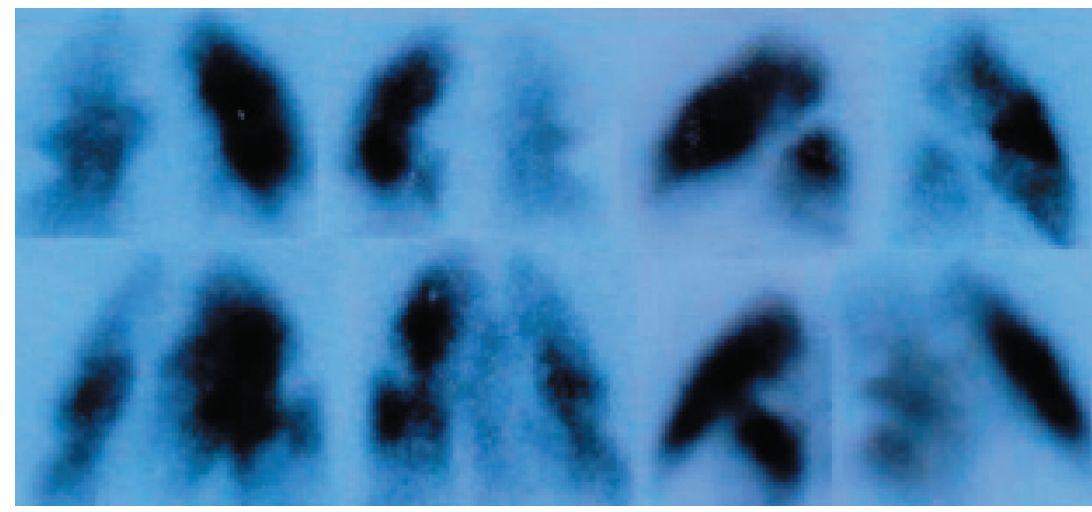

Figure I Perfusion scintigraphy pre-thrombolysis.

\section{Discussion}

Results of the VCap variables of the patients are shown in Table 1. The cut-off values were $5 \mathrm{mmHg}$ for $\mathrm{P}(\mathrm{a}$-et $) \mathrm{CO}_{2}$, 0.15 for AVDSf, ${ }^{5} 0.12$ for fDlate, ${ }^{3}$ and 7.48 for Slp III. ${ }^{7}$

In cases 1 and 2, respectively, there were changes in the post-thrombolysis variables: $\mathrm{P}\left(\mathrm{a}\right.$-et) $\mathrm{CO}_{2}$ decreased from 12.6 to $5.8 \mathrm{mmHg}$ and from 7.9 to $1.6 \mathrm{mmHg}$; AVDSf decreased from 0.46 to 0.18 and from 0.25 to 0.05 ; fDlate decreased from 0.46 to 0.21 and from 0.24 to 0.04 ; and Slp III increased from 1.75 to $5.10 \mathrm{mmHg} / \mathrm{L}$ and from 1.21 to $5.61 \mathrm{mmHg} / \mathrm{L}$ (Table 1 ).

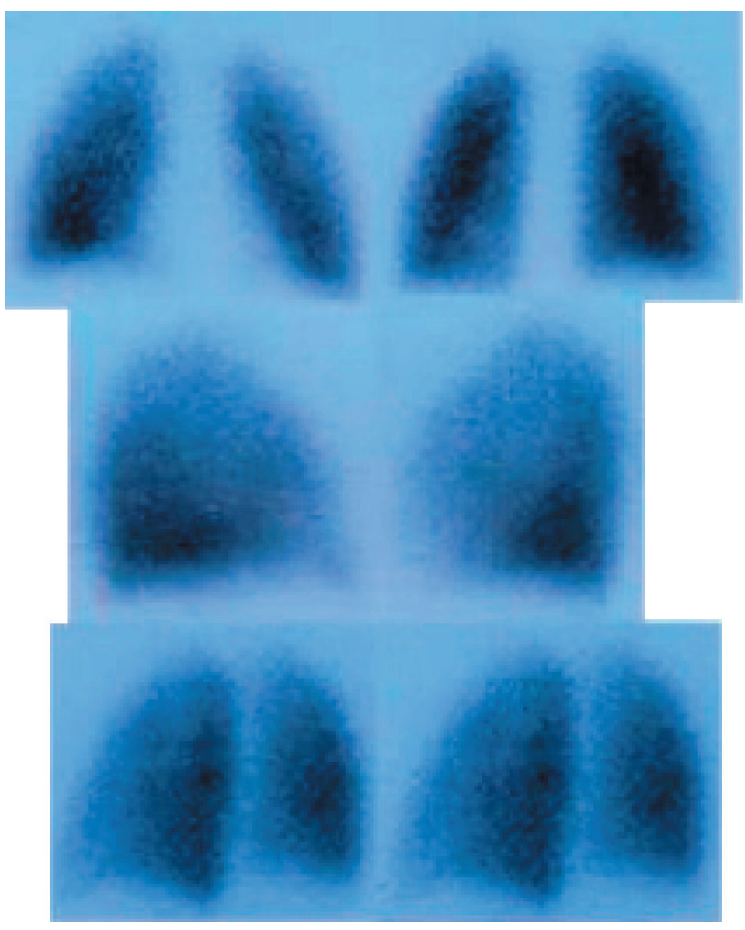

Figure 2 Perfusion scintigraphy post-7-month.
Various clinical studies have compared and evaluated physiological respiratory indices, before and after thrombolysis, in patients with acute PE. ${ }^{8-12}$ Moreira and colleagues ${ }^{8}$ calculated the pre- and post-treatment fDlate for a patient submitted to surgical embolectomy, and Verschuren and colleagues ${ }^{11}$ evaluated two patients in spontaneous ventilation, treated with chemical thrombolysis for PE. These authors observed that the fDlate and $\mathrm{P}(\mathrm{a}-\mathrm{et}) \mathrm{CO}_{2}$ presented significant post-thrombolysis variations. This was due to the fact that the opening of the vascular beds by removal of thrombotic material resulted in great improvement of pulmonary perfusion and consequent reduction in the volume of alveolar dead space. Moreira and colleagues conducted two studies: one evaluating two capnography variables (AVDSf and fDlate) in a patient with chronic pulmonary hypertension due to exacerbation of $\mathrm{PE},{ }^{12}$ and another evaluating the same capnographic variables in two patients submitted to surgical embolectomy. ${ }^{9}$ The authors demonstrated that AVDSf and fDlate both correlated with the findings of imaging studies, their values moving closer to reference values as the imaging test results improved.

The reference values obtained in healthy individuals, ${ }^{7}$ that is, the Slp III and Slp III/expired volume values, tended towards normalization in the post-thrombolysis period.

In patients with PE, the Slp III values tend to be near or below zero. After treatment for acute PE, with resolution of the occluded vascular bed, either by thromboendarterectomy or chemical thrombolysis, a post-treatment increase in Slp III values was observed, as reported in other studies.

Although rarely discussed in the literature, this variation in Slp III has been reported in clinical articles evaluating human pulmonary development, ${ }^{13}$ and in experimental studies on PE. ${ }^{14,15}$ Ream and colleagues ${ }^{13}$ demonstrated that during post-natal alveolization Slp III tends to decrease in 
Table I Variables pre-and post-thrombolysis

\begin{tabular}{|c|c|c|c|c|}
\hline \multirow{3}{*}{$\begin{array}{l}\text { Variable } \\
\text { D-dimers }\end{array}$} & \multicolumn{2}{|l|}{ Patient I } & \multicolumn{2}{|l|}{ Patient 2} \\
\hline & \multicolumn{2}{|l|}{$6981.44 \mathrm{ng} / \mathrm{ml}$} & \multicolumn{2}{|l|}{$8752.55 \mathrm{ng} / \mathrm{ml}$} \\
\hline & Pre-thrombolysis & Post-thrombolysis & Pre-thrombolysis & Post-thrombolysis \\
\hline Lung scintigraphy & Positive for acute PTE & Significant improvement & Positive for acute PTE & Negative for acute PTE \\
\hline $\mathrm{P}(\mathrm{a}-\mathrm{et}) \mathrm{CO} 2(\mathrm{mmHg})$ & 12.6 & 5.8 & 7.9 & 1.6 \\
\hline AVDSf & 0.46 & 0.18 & 0.25 & 0.05 \\
\hline fDlate & 0.46 & 0.21 & 0.24 & 0.04 \\
\hline Slope III (mmHg/L) & 1.75 & 5.10 & 1.21 & 5.61 \\
\hline \multirow[t]{2}{*}{ SIp III/Ve } & 0.0012 & 0.0049 & 0.0030 & 0.008 \\
\hline & \multicolumn{4}{|c|}{ Reference data } \\
\hline Slope III (mmHg/L) & \multicolumn{4}{|c|}{$7.48 \pm 2.36$} \\
\hline Slp III/Ve & \multicolumn{4}{|c|}{$0.014 \pm 0.006$} \\
\hline
\end{tabular}

Abbreviations: PTE, pulmonary thromboembolism; $\mathrm{P}\left(\mathrm{a}\right.$-et) $\mathrm{CO}_{2}$, arterial to end-tidal $\mathrm{CO}_{2}$ gradient; AVDSf, (end-tidal) alveolar dead space fraction; fDlate, late dead space fraction; Slp III/Ve, phase III slope of the expirogram/expired tidal volume (normalized).

value, remaining stable in adulthood. Diseases that decrease the number of alveoli available for gas exchange tend to increase Slp III. Central vascular occlusions, in turn, have the opposite effect, causing a reduction in Slp III values, which eventually fall below zero.

In experimental studies of acute PE, ${ }^{14,15}$ Slp III assumes low or even negative values and tends to increase when the disease is resolved. The application of these concepts to the present study in the analysis of the pre- and post-thrombolysis values of Slp III confirms such findings.

We also found that pre- and post-thrombolysis results were directly correlated with VCap data and with scintigraphic findings. As demonstrated by Kline and colleagues, ${ }^{4}$ when applied appropriately, VCap, used in conjunction with determination of D-dimer levels and a clinical score, can be useful in the diagnosis and follow-up of patients, especially in emergency rooms.

\section{Disclosure}

This study received part of its funding in the form of a grant from the Fundação de Amparo a Pesquisa do Estado de São Paulo (FAPESP, Foundation for the Support of Research in the State of São Paulo; Grant no. 02/05252-3).

\section{References}

1. Konstantinides S, Geibel A, Heusel G, Heinrich F, Kasper W. Heparin plus alteplase compared with heparin alone in patients with submassive pulmonary embolism. $N$ Engl J Med. 2002;347:1143-1150.

2. Konstantinides S, Geibel A, Olschewski M, et al. Association between thrombolytic treatment and the prognosis of hemodynamically stable patients with major pulmonary embolism: results of a multicenter registry. Circulation. 1997;96:882-888.

3. Eriksson L, Wollmer P, Olsson CG, et al. Diagnosis of pulmonary embolism based upon alveolar dead space analysis. Chest. 1989;96:357-362.
4. Kline JA, Webb WB, Jones AE, Hernandez-Nino J. Impact of a rapid rule-out protocol for pulmonary embolism on the rate of screening, missed cases, and pulmonary vascular imaging in an urban US emergency department. Ann Emerg Med. 2004;44:490-502.

5. Rodger MA, Bredeson CN, Jones G, et al. The bedside investigation of pulmonary embolism diagnosis study. Arch Intern Med. 2006;166:181-7.

6. Grimby G, Söderholm B. Spirometric studies in normal subjects. III. Static lung volumes and maximum voluntary ventilation in adults with a note on physical fitness. Acta Med Scand. 1963;173:199-206.

7. Paschoal IA, Moreira MM, Terzi RG, et al. Noninvasive evaluation of pulmonary disease using volumetric capnography in adult patients with cystic fibrosis. J Cyst Fibros. 2007; Supplement I:S38.

8. Moreira MM, Terzi RG, Vieira RW, Petrucci O. Fração tardia do espaço morto (fDlate) antes e após embolectomia pulmonar. Rev Bras Cir Cardiovasc. 2005;20:81-84.

9. Moreira MM, Terzi RGG, Vieira RW, et al. Variáveis capnográficas pré e pós embolectomias pulmonares - Comunicação Prévia. Rev Bras Cir Cardiovasc. 2007;22:509-512.

10. Thys F, Elamly A, Marion E, et al. $\mathrm{PaCO}_{2} / \mathrm{ETCO}_{2}$ gradient: early indicator of thrombolysis efficacy in a massive pulmonary embolism. Resuscitation. 2001;49:105-108.

11. Verschuren F, Heinonen E, Clause D, et al. Volumetric capnography as a bedside monitoring of thrombolysis in major pulmonary embolism. Intensive Care Med. 2004;30:2129-2132.

12. Moreira MM, Terzi RG, Pereira MC, Grangeia TA, Paschoal IA. Volumetric capnography as a noninvasive diagnostic procedure in acute pulmonary thromboembolism. J Bras Pneumol. 2008;34:328-332.

13. Ream RS, Schreiner MS, Neff JD, et al. Volumetric capnography in children: Influence of growth on the alveolar plateau slope. Anesthesiology. 1995;82:64-73.

14. Schreiner MS, Leksell LG, Gobran SR, et al. Microemboli reduce phase III slopes of $\mathrm{CO}_{2}$ and invert phase III slopes of infused $\mathrm{SF}_{6}$. Respir Physiol. 1993;91:137-154.

15. Moreira MM, Terzi RG, Paschoal IA, et al. Captação de oxigênio e eliminação de gás carbônico na embolia pulmonar experimental - avaliação pela gasometria arterial e capnografia volumétrica. Medicina Intensiva. 2007;(Suppl 2):57. 